\title{
Maternal hypothyroxinaemia in pregnancy is associated with obesity and adverse maternal metabolic parameters
}

\author{
Bridget A Knight ${ }^{1,3}$, Beverley M Shields ${ }^{1}$, Andrew T Hattersley ${ }^{1,3}$ and Bijay Vaidya ${ }^{2}$ \\ ${ }^{1}$ NIHR Exeter Clinical Research Facility, University of Exeter Medical School, University of Exeter, Exeter, UK, \\ ${ }^{2}$ Department of Endocrinology, Royal Devon and Exeter Hospital NHS Foundation Trust, Exeter, EX2 5DW, UK and \\ ${ }^{3}$ Research and Development Department, Royal Devon and Exeter Hospital NHS Foundation Trust, Exeter UK
}

Correspondence should be addressed to B Vaidya

Email

b.vaidya@exeter.ac.uk

\begin{abstract}
Objective: Subclinical hypothyroidism and isolated hypothyroxinaemia in pregnancy have been associated with an increased risk of gestational diabetes. We aimed to ascertain if these women have a worse metabolic phenotype than euthyroid pregnant women.

Design, subjects and methods: We recruited 956 healthy Caucasian women with singleton, non-diabetic pregnancies from routine antenatal clinics. Detailed anthropometric measurements (including BMI and skinfold thickness) and fasting blood samples (for $\mathrm{TSH}$, free thyroxine $\left(\mathrm{FT}_{4}\right)$, free triiodothyronine $\left(\mathrm{FT}_{3}\right), \mathrm{HbA} 1 \mathrm{c}$, lipid profile, plasma glucose and insulin resistance (HOMA-IR) analysis) were obtained at 28 weeks gestation.

Results: In comparison to euthyroid women $(n=741)$, women with isolated hypothyroxinaemia $(n=82)$ had significantly increased BMI (29.5 vs $\left.27.5 \mathrm{~kg} / \mathrm{m}^{2}, P<0.001\right)$, sum of skinfolds ( 57.5 vs $\left.51.3 \mathrm{~mm}, P=0.002\right)$, fasting plasma glucose (4.5 vs $4.3 \mathrm{mmol} / \mathrm{l}, P=0.01)$, triglycerides ( $2.3 \mathrm{vs} 2.0 \mathrm{mmol} / \mathrm{l}, P<0.001)$ and HOMA-IR $(2.0$ vs $1.3, P=0.001)$. Metabolic parameters in women with subclinical hypothyroidism $(n=133)$ were similar to those in euthyroid women. Maternal $\mathrm{FT}_{4}$ was negatively associated with BMI $(r=-0.22), \mathrm{HbA} 1 \mathrm{c}(r=-0.14)$, triglycerides $(r=-0.17), \mathrm{HOMA}-\mathrm{IR}(r=-0.15)$ but not total/HDL cholesterol ratio $(r=-0.03)$. Maternal $\mathrm{FT}_{3}: \mathrm{FT}_{4}$ ratio was positively associated with $\mathrm{BMI}(r=0.4), \mathrm{HbA} 1 \mathrm{c}(r=0.21)$, triglycerides $(r=0.2)$, HOMA-IR $(r=0.33)$ and total/HDL cholesterol ratio $(r=0.07)$. TSH was not associated with the metabolic parameters assessed.

Conclusions: Isolated hypothyroxinaemia, but not subclinical hypothyroidism, is associated with adverse metabolic phenotype in pregnancy, as is decreasing maternal $\mathrm{FT}_{4}$ and increasing $\mathrm{FT}_{3}: \mathrm{FT}_{4}$ ratio. These associations may be a reflection of changes in the thyroid hormone levels secondary to increase in BMI rather than changes in thyroid hormone levels affecting body weight and related metabolic parameters.
\end{abstract}

\section{Introduction}

Recently, increasing numbers of studies have shown associations between mild maternal thyroid hormone insufficiency (including subclinical hypothyroidism and isolated hypothyroxinaemia) in pregnancy and impaired neuropsychological development of the offspring, as well as several obstetric complications, such as miscarriage, preterm delivery, gestational hypertension and preeclampsia $(1,2,3)$. Several of these studies $(4,5,6)$, although not all $(7,8)$ have also shown that subclinical hypothyroidism in pregnancy is associated with an increased risk of gestational diabetes. Isolated hypothyroxinaemia has also been shown to be associated with
(C) 2016 The authors Published by Bioscientifica Ltd.

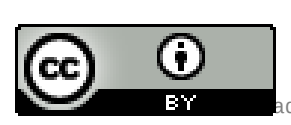

This work is licensed under a Creative Commons Attribution 3.0 Unported License. 
gestational diabetes (7), and a recent study found that lower free thyroxine $\left(\mathrm{FT}_{4}\right)$ levels and higher free triiodothyronine $\left(\mathrm{FT}_{3}\right)$ to $\mathrm{FT}_{4}$ ratios (suggesting higher peripheral deiodinase activity leading to conversion of $\mathrm{FT}_{4}$ to $\mathrm{FT}_{3}$ ) in pregnant women are associated with several adverse metabolic parameters relating to obesity, glycaemia, insulin resistance and lipid profile (9). It is possible that these adverse metabolic parameters partly explain the poor obstetric outcomes observed in pregnant women with mild maternal thyroid insufficiency $(10,11,12)$.

As little is known on whether mild maternal thyroid hormone insufficiency in pregnancy is associated with adverse metabolic parameters, our study aimed to explore the relationship between maternal thyroid hormone levels and metabolic parameters in pregnancy and ascertain if pregnant women with subclinical hypothyroidism and isolated hypothyroxinaemia have worse metabolic phenotype than euthyroid pregnant women.

\section{Subjects and methods}

\section{Subjects}

A total of 988healthy non-diabetic Caucasian women with singleton pregnancies were recruited into the Exeter Family Study of Childhood Health between 1999 and 2004 (13). These women had detailed anthropometric measurements, including height, weight and skinfold measures (triceps, biceps and subscapular) and fasting blood samples taken at 28 weeks gestation. After exclusion of women on thyroid-related medications (levothyroxine $n=18$, propylthiouracil $n=3$ ) and women with overt biochemical hypothyroidism $(n=10)$ or hyperthyroidism $(n=1)$ on the blood samples, data from 956 women were included in this study.

The study was approved by the North and East Devon Local Research Ethics Committee, and all participants gave informed written consent.

\section{Analysis of thyroid function and biochemical metabolic parameters}

Thyroid function tests (thyroid-stimulating hormone (TSH), $\mathrm{FT}_{4}$ and $\mathrm{FT}_{3}$ ) and thyroid peroxidase antibodies (TPO-Ab) were measured on the stored serum samples. Serum $\mathrm{TSH}, \mathrm{FT}_{4}$ and $\mathrm{FT}_{3}$ were analysed using the electrochemiluminescent immunoassay, run on the Modular E170 Analyzer (Roche). Intra-assay coefficients of variations were as follows: $\mathrm{TSH}<5.3 \%, \mathrm{FT}_{4}<5.3 \%$ and $\mathrm{FT}_{3}<5.1 \%$. The manufacturer's population reference ranges were as follows: TSH $0.35-4.5 \mathrm{mIU} / \mathrm{l}, \mathrm{FT}_{4}$ 11$24 \mathrm{pmol} / \mathrm{l}$, and $\mathrm{FT}_{3}$ 3.9-6.8 pmol/l. High TSH in this study of women in the third trimester was defined as $>3 \mathrm{mIU} / \mathrm{l}$, the generally accepted upper limit of the reference range in the second and third trimesters in Caucasian populations $(1,2)$. Subclinical hypothyroidism was defined as high TSH ( $>3 \mathrm{mIU} / \mathrm{l})$ with $\mathrm{FT}_{4}$ within the reference range (11-24 pmol/l). Isolated maternal hypothyroxinaemia was defined as $\mathrm{FT}_{4}$ below the 10th centile $(<10.4 \mathrm{pmol} / \mathrm{l})$ with TSH within the reference range. TPO-Abs were analysed using the competitive immunoassay (Roche), and a titre above $34 \mathrm{IU} / \mathrm{ml}$ was considered positive.

Fasting plasma glucose, serum insulin and lipid profile and glycosylated haemoglobin (HbA1c) were analysed in the fresh blood samples, as previously described (13). We analysed homeostasis model of assessment for insulin resistance (HOMA-IR) to estimate fasting insulin sensitivity using the following formula: fasting serum insulin $(\mathrm{mIU} / \mathrm{l}) \times$ fasting plasma glucose $(\mathrm{mmol} / \mathrm{l}) / 22.5$.

\section{Statistical analysis}

We assessed variables for distribution and log-transformed where they were not normally distributed. We used the independent sample $t$-test to compare metabolic parameters in women with isolated hypothyroxinaemia or subclinical hypothyroidism and women with normal thyroid function, and in euthyroid women with and without TPO-Ab. We used the $\chi^{2}$ test to assess TPOAb-positive proportions in each group. We used Pearson's correlation to assess associations between variables, and multiple linear regression analysis to assess independent associations between variables. As smoking and TPO-Ab are potential confounders affecting thyroid function, we have also included these factors in the regression analysis $(14,15)$. We used independent samples $t$-test to compare metabolic parameters between women with lower and upper quartiles of $\mathrm{FT}_{4}$ and between women with lower and upper quartiles of $\mathrm{FT}_{3}: \mathrm{FT}_{4}$ ratio. We carried out statistical analyses using SPSS (version 22).

\section{Results}

\section{Study population}

Participants had a mean (s.D.) age of 30.1 (5.1) years and BMI of $27.9(4.6) \mathrm{kg} / \mathrm{m}^{2} ; 46 \%$ were primiparous and $14 \%$ smoked during pregnancy. 
Metabolic parameters in pregnant women with subclinical hypothyroidism and isolated hypothyroxinaemia

A total of $133(13.9 \%)$ women in our cohort had subclinical hypothyroidism and $82(8.6 \%)$ had isolated hypothyroxinaemia.

There was no difference in metabolic parameters between women with subclinical hypothyroidism and euthyroid women (Table 1). Metabolic parameters in women with subclinical hypothyroidism who had TSH greater than $5 \mathrm{mIU} / \mathrm{l}(n=12)$ were also similar to those in euthyroid women (data not shown).

When compared to euthyroid women, women with maternal isolated hypothyroxinaemia had significantly increased BMI (29.5 vs $\left.27.5 \mathrm{~kg} / \mathrm{m}^{2}, P<0.001\right)$, sum of skinfolds (57.5 vs $51.3 \mathrm{~mm}, P=0.002)$, fasting plasma glucose ( 4.5 vs $4.3 \mathrm{mmol} / \mathrm{l}, P=0.01$ ), triglycerides ( $2.3 \mathrm{vs}$ $2.0 \mathrm{mmol} / \mathrm{l}, \quad P<0.001)$ and HOMA-IR $(2.0$ vs 1.3 , $P=0.001)$, and borderline increased HbA1c (29.9 vs $28.7 \mathrm{mmol} / \mathrm{mol}, P=0.05$ ) (Table 1 ).

\section{Association between maternal thyroid hormone levels and metabolic parameters}

In bivariate analyses, maternal $\mathrm{FT}_{4}$ was negatively associated with BMI $(r=-0.22, P<0.001)$, sum of skinfolds $(r=-0.22, P<0.001)$, HbA1c $(r=-0.14, P<0.001)$, fasting plasma glucose $(r=-0.13, P<0.001)$, triglycerides $(r=-0.17, P<0.001)$, HOMA-IR $(r=-0.15, P<0.001)$ but not Total/HDL cholesterol ratio $(r=-0.03, P=0.3)$ (Table 2). Maternal $\mathrm{FT}_{3}: \mathrm{FT}_{4}$ ratio was positively associated with BMI $(r=0.40)$, sum of skinfolds $(r=0.37)$, HbA1c $(r=0.21)$, fasting plasma glucose $(r=0.24)$, triglycerides $(r=0.2)$ and HOMA-IR $(r=0.33)(P<0.001$ for all $)$ and Total/HDL cholesterol $(r=0.07, P=0.04)$. Maternal TSH in pregnancy was not correlated with any of the maternal metabolic parameters assessed.

Women with the lowest $\mathrm{FT}_{4}$ quartile and the highest $\mathrm{FT}_{3}: \mathrm{FT}_{4}$ ratio quartile had significantly higher BMI, sum of skinfolds, HbA1c, fasting plasma glucose, triglycerides and HOMA-IR as compared to women with the highest $\mathrm{FT}_{4}$ quartile and the lowest $\mathrm{FT}_{3}: \mathrm{FT}_{4}$ ratio quartile respectively $(P \leq 0.001$ for all) (Table 3$)$. There was no difference in total/HDL cholesterol ratio between groups.

In multivariable regression analyses (Table 4), $\mathrm{FT}_{4}$ was independently associated with $\mathrm{BMI}, \mathrm{HbA1c}$, triglycerides and smoking during pregnancy, but not HOMA-IR. $\mathrm{FT}_{3}: \mathrm{FT}_{4}$ ratio was independently associated with BMI, HbA1c, HOMA-IR, and borderline associated with smoking during pregnancy, but not triglycerides or total/HDL cholesterol.

\section{Association between maternal TPO-Ab status and metabolic parameters}

Amongst the euthyroid women, there was no difference in metabolic parameters between TPO-Ab-positive $(n=37)$ and TPO-Ab ( $n=696)$-negative women (data not shown).

Table 1 Comparison of thyroid function and metabolic parameters between euthyroid mothers and those with subclinical hypothyroidism and euthyroid mothers and those with isolated hypothyroxinaemia in pregnancy (data presented as mean \pm s.D. or a geometric mean (s.D. range) except for TPO-Ab positivity which is presented as percentage). The bold values are statistically significant results.

\begin{tabular}{|c|c|c|c|c|c|}
\hline Metabolic parameters & $\begin{array}{l}\text { Euthyroid controls } \\
\qquad(n=741)\end{array}$ & $\begin{array}{c}\text { Subclinical } \\
\text { hypothyroidism } \\
(n=133)\end{array}$ & $P_{\text {value }}^{b}$ & $\begin{array}{c}\text { Isolated } \\
\text { hypothyroxinaemia } \\
(n=82)\end{array}$ & P value $^{\mathrm{b}}$ \\
\hline $\mathrm{TSH}^{\mathrm{a}}(\mathrm{mIU} / \mathrm{l})$ & $1.6(0.9,2.7)$ & $3.7(3.1,4.5)$ & $<0.001$ & $1.8(1.3,2.5)$ & 0.001 \\
\hline $\mathrm{FT}_{4}(\mathrm{pmol} / \mathrm{l})$ & $12.5(1.4)$ & $11.9(1.5)$ & $<0.001$ & $9.7(0.5)$ & $<0.001$ \\
\hline $\mathrm{FT}_{3}(\mathrm{pmol} / \mathrm{l})$ & $4.2(0.5)$ & $4.2(0.5)$ & 0.2 & $4.1(0.4)$ & 0.04 \\
\hline TPO-Ab positive (\%) & 5.0 & 13.7 & 0.001 & 6.0 & 0.6 \\
\hline BMI $\left(\mathrm{kg} / \mathrm{m}^{2}\right)^{\mathrm{a}}$ & $27.5(23.4-32.4)$ & $27.5(23.7-32.1)$ & 0.7 & $29.5(25.1-34.7)$ & $<0.001$ \\
\hline Sum of skinfolds $(\mathrm{mm})^{a}$ & $51.3(37.2-70.8)$ & $50.1(33.3-69.2)$ & 0.9 & $57.5(40.7-81.3)$ & 0.002 \\
\hline HbA1c (mmol/mol) & $28.7(3.7)$ & $28.5(3.9)$ & 0.7 & $29.9(4.6)$ & 0.05 \\
\hline Fasting plasma glucose $(\mathrm{mmol} / \mathrm{l})$ & $4.3(0.4)$ & $4.3(3.8)$ & 0.8 & $4.5(0.4)$ & 0.01 \\
\hline Triglycerides $(\mathrm{mmol} / \mathrm{l})^{\mathrm{a}}$ & $2.0(1.5-2.8)$ & $2.0(1.4-2.8)$ & 0.7 & $2.3(1.7-3.3)$ & $<0.001$ \\
\hline HOMA-IR & $1.3(0.7-2.0)$ & $1.0(0.8-2.0)$ & 0.4 & $2.0(0.9-2.8)$ & 0.001 \\
\hline Total/HDL cholesterol ratio & $3.4(0.9)$ & $3.3(0.9)$ & 0.4 & $3.5(1.0)$ & 0.1 \\
\hline
\end{tabular}


Table 2 Correlations between maternal $\mathrm{TSH}, \mathrm{FT}_{4}, \mathrm{FT}_{3}: \mathrm{FT}_{4}$ ratio and metabolic parameters at 28 weeks gestation. The bold values are statistically significant results.

\begin{tabular}{l} 
Metabolic parameters \\
\hline BMI $\left(\mathrm{kg} / \mathrm{m}^{2}\right)^{\mathrm{a}}$ \\
Sum of skinfolds $(\mathrm{mm})^{\mathrm{a}}$ \\
HbA1c $(\mathrm{mmol} / \mathrm{mol})$ \\
Fasting plasma glucose $(\mathrm{mmol} / \mathrm{l})$ \\
Triglycerides $(\mathrm{mmol} / \mathrm{l})^{\mathrm{a}}$ \\
HOMA-IR $^{\mathrm{a}}$ \\
Total/HDL cholesterol ratio
\end{tabular}

aDenotes log-transformed data.

\section{Discussion}

In this study of healthy non-diabetic pregnant women, we found that women with isolated hypothyroxinaemia have worse metabolic parameters with increased obesity, glycaemia, triglycerides and insulin resistance compared to euthyroid women. In contrast, subclinical hypothyroidism in pregnancy was not associated with these adverse metabolic parameters. We also identified lower maternal serum $\mathrm{FT}_{4}$ and higher $\mathrm{FT}_{3}: \mathrm{FT}_{4}$ ratio (indicating an increased peripheral deiodinase activity leading to conversion of $\mathrm{FT}_{4}$ to $\mathrm{FT}_{3}$ ) associated with adverse metabolic parameters.

Thyroid hormones play key roles in regulating metabolic processes and energy homeostasis in the body (16). It is well known that overt thyroid dysfunction (hypothyroidism or hyperthyroidism) affects body weight, and recent studies have shown that even small variations in thyroid hormone levels within the reference range are associated with significant metabolic consequences and changes in body weight $(16,17)$. In the mouse model of type 2 diabetes, thyroid hormone has been shown to improve glycaemia and insulin sensitivity (18). Our

\begin{tabular}{c}
\hline $\begin{array}{c}\mathbf{F T}_{\mathbf{4}} \\
r(P \text { value })\end{array}$ \\
$-0.22(<0.001)$ \\
$-0.22(<0.001)$ \\
$-0.14(<0.001)$ \\
$-0.13(<0.001)$ \\
$-0.17(<0.001)$ \\
$-0.15(<0.001)$ \\
$-0.03(0.3)$
\end{tabular}

\begin{tabular}{l}
\hline $\mathbf{F T}_{3}: \mathrm{FT}_{\mathbf{4}}$ ratio \\
$r(P$ value $)$
\end{tabular}

finding of the inverse correlation between maternal serum $\mathrm{FT}_{4}$ and maternal $\mathrm{BMI}$ is consistent with previous studies in the pregnant and non-pregnant populations $(19,20,21,22,23)$. In the general population, low $\mathrm{FT}_{4}$ as well as high $\mathrm{FT}_{3}: \mathrm{FT}_{4}$ ratio have also been shown to be associated with adverse metabolic parameters, including less favourable lipid profile, blood pressure and insulin resistance $(24,25,26,27,28)$. It is thought that lower $\mathrm{FT}_{4}$ levels are compensated by a higher peripheral deiodinase activity resulting in higher conversion of $\mathrm{FT}_{4}$ to active thyroid hormone $\mathrm{FT}_{3}$ and higher $\mathrm{FT}_{3}: \mathrm{FT}_{4}$ ratio (20). In a recent study of 321 healthy pregnant women without a history of thyroid dysfunction, Bassols et al. (9) found that decreasing $\mathrm{FT}_{4}$ and increasing $\mathrm{FT}_{3}: \mathrm{FT}_{4}$ ratios are similarly associated with less favourable metabolic profile. In addition to confirming the associations in a larger cohort of pregnant women, our study also demonstrates the presence of worse metabolic parameters in women with maternal hypothyroxinaemia as compared to euthyroid women. In contrast, despite several studies $(4,5,6)$, but not all $(7,8)$, showing association between subclinical hypothyroidism in pregnancy and gestational diabetes,

Table 3 Comparisons between upper and lower $\mathrm{FT}_{4}$ and $\mathrm{FT}_{3}: \mathrm{FT}_{4}$ ratio quartiles, and maternal metabolic parameters (data presented as mean \pm s.D. or ${ }^{\text {a }}$ geometric mean (s.D. range)). Bold values are statistically significant results.

\begin{tabular}{|c|c|c|c|c|c|c|}
\hline \multirow[b]{2}{*}{ Metabolic parameters } & \multicolumn{2}{|c|}{$\mathbf{F T}_{4}$} & \multirow[b]{2}{*}{$P$ value } & \multicolumn{2}{|c|}{$\mathrm{FT}_{3}: \mathrm{FT}_{4}$ ratio } & \multirow[b]{2}{*}{$P$ value } \\
\hline & Lower quartile & Upper quartile & & Lower quartile & Upper quartile & \\
\hline BMI $\left(\mathrm{kg} / \mathrm{m}^{2}\right)^{a}$ & $28.8(24.6-33.9)$ & $\overline{26.9(22.9-31.6)}$ & $<0.001$ & $25.1(21.9-28.8)$ & $30.2(26.7-35.5)$ & $<0.001$ \\
\hline Sum of skinfolds $(\mathrm{mm})^{a}$ & $57.4(41.7-79.4)$ & $47.9(34.7-66.1)$ & $<0.001$ & $44.7(32.4-61.7)$ & $63.1(45.7-87.1)$ & $<0.001$ \\
\hline $\mathrm{HbA} 1 \mathrm{c}(\mathrm{mmol} / \mathrm{mol})$ & $29.5(4.1)$ & $28.1(3.8)$ & 0.001 & $27.9(3.6)$ & $29.9(4.4)$ & $<0.001$ \\
\hline $\begin{array}{l}\text { Fasting plasma glucose } \\
(\mathrm{mmol} / \mathrm{l})\end{array}$ & $4.4(0.4)$ & $4.3(0.4)$ & $<0.001$ & $4.2(0.3)$ & $4.5(0.4)$ & $<0.001$ \\
\hline Triglyceride $(\mathrm{mmol} / \mathrm{l})^{a}$ & $2.2(1.6-3.1)$ & $1.9(1.4-2.5)$ & $<0.001$ & $1.9(1.4-2.6)$ & $2.2(1.6-3.1)$ & $<0.001$ \\
\hline HOMA-IR ${ }^{a}$ & $2.0(1.0-2.6)$ & $1.0(0.8-2.0)$ & $<0.001$ & $1.0(0.6-1.6)$ & $2.0(1.0-2.5)$ & $<0.001$ \\
\hline Total/HDL cholesterol ratio & $3.0(1.8)$ & $3.3(0.7)$ & 0.17 & $3.3(0.9)$ & $3.4(1.0)$ & 0.24 \\
\hline
\end{tabular}


Table 4 Multivariable regression analysis to demonstrate the relationships between maternal $\mathrm{FT}_{4}$ and $\mathrm{FT}_{3}: \mathrm{FT}_{4}$ ratio with metabolic parameters. Partial $R$ is the adjusted correlation coefficient. Bold values are statistically significant results.

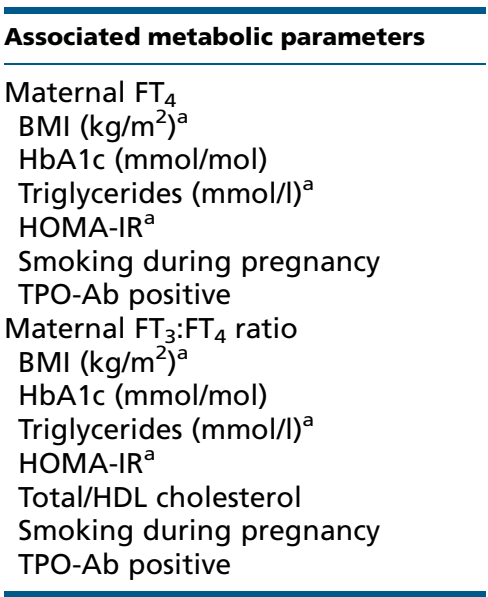

\begin{tabular}{|c|c|}
\hline Partial $R$ & $\beta$ \\
\hline-0.13 & -1.55 \\
\hline-0.09 & -0.04 \\
\hline-0.10 & -0.49 \\
\hline-0.02 & -0.06 \\
\hline 0.09 & 0.43 \\
\hline-0.004 & -0.02 \\
\hline 0.26 & 0.10 \\
\hline 0.11 & 0.001 \\
\hline 0.07 & 0.01 \\
\hline 0.14 & 0.02 \\
\hline-0.07 & -0.004 \\
\hline 0.07 & 0.01 \\
\hline 0.02 & 0.003 \\
\hline
\end{tabular}

\begin{tabular}{c}
$95 \% \mathrm{Cl}$ for $\beta$ \\
$-2.43,-0.68$ \\
$-0.07,-0.01$ \\
$-0.84,-0.13$ \\
$-0.31,0.21$ \\
$0.10,0.77$ \\
$-0.47,0.41$ \\
$0.07,0.12$ \\
$0.00,0.002$ \\
$-0.001,0.02$ \\
$0.007,0.023$ \\
$-0.009,0.000$ \\
$0.00,0.02$ \\
$-0.01,0.02$ \\
\hline
\end{tabular}

$\begin{array}{r}\multicolumn{1}{c}{\boldsymbol{t}} \\ -3.47 \\ -2.54 \\ -2.71 \\ -0.43 \\ 2.52 \\ -0.10 \\ \\ 7.18 \\ 2.92 \\ 1.86 \\ 3.72 \\ -3.52 \\ 1.98 \\ 0.80 \\ \hline\end{array}$

\begin{tabular}{ll}
\hline \multicolumn{1}{|c}{} \\
\hline \\
$\mathbf{0 . 0 0 1}$ \\
$\mathbf{0 . 0 1}$ \\
$\mathbf{0 . 0 0 7}$ \\
0.7 \\
$\mathbf{0 . 0 1}$ \\
0.9 \\
$<\mathbf{0 . 0 0 1}$ \\
$\mathbf{0 . 0 0 4}$ \\
0.06 \\
$<\mathbf{0 . 0 0 1}$ \\
0.06 \\
0.05 \\
0.9
\end{tabular}

${ }^{a}$ Variable transformed using natural logs (allowing $\beta$ coefficients to be interpreted in terms of percentage change).

we were unable to demonstrate that pregnant women with subclinical hypothyroidism have less favourable metabolic parameters than euthyroid pregnant women. The possible explanations for this discrepant observations include differences in study populations (for example, women with gestational diabetes were excluded in our study) and different TSH cut-off levels used to define subclinical hypothyroidism.

As it is a cross-sectional observational study, our study cannot ascertain that the observed less favourable metabolic parameters are caused by changes in the thyroid hormone levels. Indeed, it is possible that the associations between maternal thyroid function and metabolic parameters are mediated by obesity, as glycaemia, insulin resistance and dyslipidaemia are closely associated with obesity. Several lines of evidence support the hypothesis that changes in thyroid hormone levels are the consequence rather than the cause of changes in body weight. Increased subcutaneous fat has been shown to be associated with lower $\mathrm{FT}_{4}$ and higher TSH levels in euthyroid adults (29). A study in iodine-deficient pregnant women showed that obesity is associated with an increased risk of maternal hypothyroxinaemia (30). It is thought that obesity stimulates peripheral deiodinase activity as an adaptation process to increase energy expenditure resulting in an increased conversion of $\mathrm{FT}_{4}$ to $\mathrm{FT}_{3}$ and high $\mathrm{FT}_{3}: \mathrm{FT}_{4}$ ratio (22). More importantly, weight loss following dietary and life-style interventions have been shown to be associated with changes in thyroid hormone levels, including decreases in $\mathrm{FT}_{3}$ level and $\mathrm{FT}_{3}: \mathrm{FT}_{4}$ ratio $(3132)$. Together, these observations suggest that pregnant women should be encouraged to avoid excess weight gain to prevent maternal hypothyroxinaemia.

We acknowledge a number of other limitations in this study. First, we carried out thyroid function tests on stored serum samples; however, it has been shown that serum $\mathrm{TSH}, \mathrm{FT}_{4}, \mathrm{FT}_{3}$ and TPO-Ab concentrations remain stable after storage for several years (33). Second, women with gestational diabetes were excluded from the study during recruitment, therefore we were unable to analyse whether the observed association between isolated hypothyroxinaemia and adverse metabolic parameters extended to an increased risk of gestational diabetes. Finally, we were also unable to assess the potential impact of iodine deficiency on our results due to a lack of urinary iodine concentration data.

In conclusion, this study demonstrates that maternal isolated hypothyroxinaemia, but not subclinical hypothyroidism, is associated with adverse metabolic parameters in pregnancy. The association between low serum thyroxine level and adverse metabolic parameters may be a reflection of changes in the thyroid hormone levels secondary to increases in BMI rather than changes in thyroid hormone levels affecting body weight and related metabolic parameters.

Declaration of interest

The authors declare that there is no conflict of interest that could be perceived as prejudicing the impartiality of the research reported. 
Funding

The Endocrine Research Fund funded the thyroid function tests. B A Knight, B M Shields and A T Hattersley are funded by the National Institute for Health Research (NIHR) as core members of the NIHR Exeter Clinical Research Facility. Work of B Vaidya is supported by the Research and Development Department of the Royal Devon and Exeter NHS Foundation Trust.

\section{References}

1 Stagnaro-Green A, Abalovich M, Alexander E, Azizi F, Mestman J, Negro R, Nixon A, Pearce EN, Soldin OP, Sullivan S et al. American Thyroid Association Taskforce on Thyroid Disease During Pregnancy \& Postpartum. Guidelines of the American Thyroid Association for the diagnosis and management of thyroid disease during pregnancy and postpartum. Thyroid 201121 1081-1125. (doi:10.1089/thy.2011.0087)

2 De Groot L, Abalovich M, Alexander EK, Amino N, Barbour L, Cobin RH, Eastman CJ, Lazarus JH, Luton D, Mandel SJ et al. Management of thyroid dysfunction during pregnancy and postpartum: an Endocrine Society clinical practice guideline. Journal of Endocrinology and Metabolism 201297 2543-2565. (doi:10.1210/jc.2011-2803)

3 Lazarus J, Brown RS, Daumerie C, Hubalewska-Dydejczyk A, Negro R \& Vaidya B. European thyroid association guidelines for the management of subclinical hypothyroidism in pregnancy and in children. European Thyroid Journal 20143 76-94. (doi:10.1159/000362597)

4 Karakosta P, Alegakis D, Georgiou V, Roumeliotaki T, Fthenou E, Vassilaki M, Boumpas D, Castanas E, Kogevinas M \& Chatzi L. Thyroid dysfunction and autoantibodies in early pregnancy are associated with increased risk of gestational diabetes and adverse birth outcomes. Journal of Endocrinology and Metabolism 201297 4464-4472. (doi:10.1210/jc.2012-2540)

5 Tudela CM, Casey BM, McIntire DD \& Cunningham FG. Relationship of subclinical thyroid disease to the incidence of gestational diabetes. Obstetrics and Gynecology 2012119 983-988. (doi:10.1097/AOG. 0b013e318250aeeb)

6 Toulis KA, Stagnaro-Green A \& Negro R. Maternal subclinical hypothyroidsm and gestational diabetes mellitus: a meta-analysis. Endocrine Practice 201420 703-714. (doi:10.4158/EP13440.RA)

7 Cleary-Goldman J, Malone FD, Lambert-Messerlian G, Sullivan L, Canick J, Porter TF, Luthy D, Gross S, Bianchi DW \& D'Alton ME. Maternal thyroid hypofunction and pregnancy outcome. Obstetrics and Gynecology 2008112 85-92. (doi:10.1097/AOG.0b013e3181788dd7)

8 Chen LM, Du WJ, Dai J, Zhang Q, Si GX, Yang H, Ye EL, Chen QS, Yu LC, Zhang $\mathrm{C}$ et al. Effects of subclinical hypothyroidism on maternal and perinatal outcomes during pregnancy: a single-center cohort study of a Chinese population. PLOS ONE 20149 e109364. (doi:10.1371/ journal.pone.0109364)

9 Bassols J, Prats-Puig A, Soriano-Rodriguez P, Garcia-Gonzalez MM, Reid J, Martinez-Pascual M, Mateos-Comeron F, de Zegher F, Ibanez L \& Lopez-Bermejo A. Lower free thyroxin associates with a less favorable metabolic phenotype in healthy pregnant women. Journal of Endocrinology and Metabolism 201196 3717-3723. (doi:10.1210/ jc.2011-1784)

10 Dennedy MC, Avalos G, O'Reilly MW, O'Sullivan EP, Gaffney G \& Dunne F. ATLANTIC-DIP: raised maternal body mass index (BMI) adversely affects maternal and fetal outcomes in glucose-tolerant women according to International Association of Diabetes and Pregnancy Study Groups (IADPSG) criteria. Journal of Endocrinology and Metabolism 201297 E608-E612. (doi:10.1210/jc.2011-2674)

11 Vrijkotte TG, Krukziener N, Hutten BA, Vollebregt KC, van Eijsden M \& Twickler MB. Maternal lipid profile during early pregnancy and pregnancy complications and outcomes: the ABCD study. Journal of
Endocrinology and Metabolism 201297 3917-3925. (doi:10.1210/ jc.2012-1295)

12 Tian L, Shen H, Lu Q, Norman RJ \& Wang J. Insulin resistance increases the risk of spontaneous abortion after assisted reproduction technology treatment. Journal of Endocrinology and Metabolism 200792 1430-1433. (doi:10.1210/jc.2006-1123)

13 Knight B, Shields BM \& Hattersley AT. The Exeter Family Study of Childhood Health (EFSOCH): study protocol and methodology. Paediatric and Perinatal Epidemiology 200620 172-179. (doi:10.1111/j. 1365-3016.2006.00701.x)

14 Shields B, Hill A, Bilous M, Knight B, Hattersley AT, Bilous RW \& Vaidya B. Cigarette smoking during pregnancy is associated with alterations in maternal and fetal thyroid function. Journal of Endocrinology and Metabolism 200994 570-574. (doi:10.1210/jc.2008-0380)

15 Mannisto T, Hartikainen AL, Vaarasmaki M, Bloigu A, Surcel HM, Pouta A, Jarvelin MR, Ruokonen A \& Suvanto E. Smoking and early pregnancy thyroid hormone and anti-thyroid antibody levels in euthyroid mothers of the Northern Finland Birth Cohort 1986. Thyroid 201222 944-950. (doi:10.1089/thy.2011.0377)

16 Laurberg P, Knudsen N, Andersen S, Carle A, Pedersen IB \& Karmisholt J. Thyroid function and obesity. European Thyroid Journal 20121 159-167. (doi:10.1159/000342994)

17 Taylor PN, Razvi S, Pearce SH \& Dayan CM. Clinical review: a review of the clinical consequences of variation in thyroid function within the reference range. Journal of Endocrinology and Metabolism 201398 3562-3571. (doi:10.1210/jc.2013-1315)

18 Lin Y \& Sun Z. Thyroid hormone potentiates insulin signaling and attenuates hyperglycemia and insulin resistance in a mouse model of type 2 diabetes. British Journal of Pharmacology 2011162 597-610. (doi:10.1111/j.1476-5381.2010.01056.x)

19 Mannisto T, Surcel HM, Ruokonen A, Vaarasmaki M, Pouta A, Bloigu A, Jarvelin MR, Hartikainen AL \& Suvanto E. Early pregnancy reference intervals of thyroid hormone concentrations in a thyroid antibodynegative pregnant population. Thyroid 201121 291-298. (doi:10.1089/ thy.2010.0337)

20 Haddow JE, Craig WY, Palomaki GE, Neveux LM, LambertMesserlian G, Canick JA, Malone FD \& D'Alton ME. First \& Second Trimester Risk Of Aneuploidy Faster Research C. Impact of adjusting for the reciprocal relationship between maternal weight and free thyroxine during early pregnancy. Thyroid 201323 225-230. (doi:10.1089/thy. 2012.0440)

21 Haddow JE, Craig WY, Neveux LM, Haddow HR, Palomaki GE, LambertMesserlian G, Malone FD \& D'Alton ME. First \& Second Trimester Risk of Aneuploidy Research C. Implications of High Free Thyroxine (FT4) concentrations in euthyroid pregnancies: the FaSTER trial. Journal of Clinical Endocrinology and Metabolism 201499 2038-2044. (doi:10.1210/ jc.2014-1053)

22 Haddow JE, Neveux LM, Palomaki GE, Lambert-Messerlian G, Malone FD \& D'Alton ME. An inverse relationship between weight and free thyroxine during early gestation among women treated for hypothyroidism. Thyroid 201525 949-953. (doi:10.1089/thy.2015.0085)

23 Knudsen N, Laurberg P, Rasmussen LB, Bulow I, Perrild H, Ovesen L \& Jorgensen T. Small differences in thyroid function may be important for body mass index and the occurrence of obesity in the population. Journal of Clinical Endocrinology and Metabolism 200590 4019-4024. (doi:10.1210/jc.2004-2225)

24 Roos A, Bakker SJ, Links TP, Gans RO \& Wolffenbuttel BH. Thyroid function is associated with components of the metabolic syndrome in euthyroid subjects. Journal of Clinical Endocrinology and Metabolism 2007 92 491-496. (doi:10.1210/jc.2006-1718)

25 De Pergola G, Ciampolillo A, Paolotti S, Trerotoli P \& Giorgino R. Free triiodothyronine and thyroid stimulating hormone are directly associated with waist circumference, independently of insulin resistance, metabolic parameters and blood pressure in overweight and obese women. Clinical Endocrinology 200767 265-269. (doi:10.1111/ j.1365-2265.2007.02874.x) 
26 Garduno-Garcia Jde J, Alvirde-Garcia U, Lopez-Carrasco G, Padilla Mendoza ME, Mehta R, Arellano-Campos O, Choza R, Sauque L, GaraySevilla ME, Malacara JM, Gomez-Perez FJ \& Aguilar-Salinas CA. TSH and free thyroxine concentrations are associated with differing metabolic markers in euthyroid subjects. European Journal of Endocrinology 2010 163 273-278. (doi:10.1530/EJE-10-0312)

27 Mehran L, Amouzegar A, Tohidi M, Moayedi M \& Azizi F. Serum free thyroxine concentration is associated with metabolic syndrome in euthyroid subjects. Thyroid 201424 1566-1574. (doi:10.1089/thy. 2014.0103)

28 Roef GL, Rietzschel ER, Van Daele CM, Taes YE, De Buyzere ML, Gillebert TC \& Kaufman JM. Triiodothyronine and free thyroxine levels are differentially associated with metabolic profile and adiposityrelated cardiovascular risk markers in euthyroid middle-aged subjects. Thyroid 201424 223-231. (doi:10.1089/thy.2013.0314)

29 Alevizaki M, Saltiki K, Voidonikola P, Mantzou E, Papamichael C \& Stamatelopoulos K. Free thyroxine is an independent predictor of subcutaneous fat in euthyroid individuals. European Journal of Endocrinology 2009161 459-465. (doi:10.1530/EJE-09-0441)
30 Gowachirapant S, Melse-Boonstra A, Winichagoon P \& Zimmermann MB. Overweight increases risk of first trimester hypothyroxinaemia in iodine-deficient pregnant women. Maternal \& Child Nutrition 201410 61-71. (doi:10.1111/mcn.12040)

31 Wolters B, Lass N \& Reinehr T. TSH and free triiodothyronine concentrations are associated with weight loss in a lifestyle intervention and weight regain afterwards in obese children. European Journal of Endocrinology 2013168 323-329. (doi:10.1530/EJE-12-0981)

32 Agnihothri RV, Courville AB, Linderman JD, Smith S, Brychta R, Remaley A, Chen KY, Simchowitz L \& Celi FS. Moderate weight loss is sufficient to affect thyroid hormone homeostasis and inhibit its peripheral conversion. Thyroid 201424 19-26. (doi:10.1089/ thy.2013.0055)

33 Mannisto T, Surcel HM, Bloigu A, Ruokonen A, Hartikainen AL, Jarvelin MR, Pouta A, Vaarasmaki M \& Suvanto-Luukkonen E. The effect of freezing, thawing, and short- and long-term storage on serum thyrotropin, thyroid hormones, and thyroid autoantibodies: implications for analyzing samples stored in serum banks. Clinica Chimica Acta 200753 1986-1987.

Received 26 August 2015

Revised version received 3 October 2015

Accepted 14 October 2015 